\title{
Laparoscopic treatment of intestinal malrotation in neonates and infants: retrospective study
}

\author{
Jeroen Hagendoorn • Daisy Vieira-Travassos • \\ David van der Zee
}

Received: 26 February 2010/ Accepted: 20 May 2010/Published online: 18 June 2010

(c) The Author(s) 2010. This article is published with open access at Springerlink.com

\begin{abstract}
Background Intestinal malrotation in neonates or infants may require urgent surgical treatment, especially when volvulus and vascular compromise of the midgut are suspected. Successful laparoscopic management of malrotation has been described in a number of case reports. It remains unclear, however, whether laparoscopy for the treatment of malrotation has a success rate equal to that of open surgery and what relative risks exist in terms of conversion and redo surgery in larger numbers of patients. This report describes a retrospective analysis of the clinical outcome for 45 children who underwent laparoscopic treatment of intestinal malrotation at the authors' institution.

Methods The 45 patients in this series, ages several days to 13 years, underwent a diagnostic laparoscopy for suspected intestinal malrotation. For 37 patients, malrotation with or without volvulus was diagnosed. All these patients underwent laparoscopic derotation and Ladd's procedure.

Results Successful laparoscopic treatment of intestinal malrotation could be performed in $75 \%$ of the cases $(n=28)$, and conversion to an open procedure was necessary in $25 \%$ of the cases $(n=9)$. The median hospital stay was 11 days (range, 2-60 days). Postoperative clinical relapse due to recurrence of malrotation, volvulus, or both occurred for $19 \%$ of the laparoscopically treated patients $(n=7)$. These patients underwent laparoscopic $(n=1)$ or open $(n=6)$ redo surgery.
\end{abstract}

J. Hagendoorn · D. Vieira-Travassos · D. van der Zee $(\bowtie)$ Department of Pediatric Surgery, Wilhelmina Children's Hospital/University Medical Center, P.O. Box 85090, 3508 AB Utrecht, The Netherlands

e-mail: d.c.vanderzee@umcutrecht.nl

J. Hagendoorn

e-mail: j.hagendoorn@umcutrecht.nl
Conclusion Diagnostic laparoscopy is the procedure of choice when intestinal malrotation is suspected. If present, malrotation can be treated adequately with laparoscopic surgery in the majority of cases. Nevertheless, to prevent recurrence of malrotation or volvulus, a low threshold for conversion to an open procedure is mandated.

Keywords Gastrointestinal surgery - Laparoscopy · Malrotation · Neonates

Intestinal malrotation comprises a spectrum of rotational abnormalities that may lead to a variety of clinical symptoms in neonates, infants, and older children [1-3]. Embryologically, intestinal nonrotation and incomplete rotation coincide with a narrow base of the mesentery. In neonates and young children, this may lead to midgut volvulus and duodenal obstruction (due to Ladd's peritoneal bands or intrinsic duodenal obstruction), which can present acutely. In older children, intermittent volvulus and bowel obstruction can present with chronic abdominal symptoms.

In any case, the operative management consists of derotation, widening of the mesenteric base, and, where appropriate, division of Ladd's bands. An incidental appendectomy may be performed as well.

The excellent feasibility of laparoscopy in pediatric gastrointestinal surgery has led to a dramatic increase in the scope of procedures performed laparoscopically [4]. More than a decade ago, we first described the laparoscopic management of intestinal malrotation with midgut volvulus in a neonate [5]. Since then, a number of case reports and several smaller series have confirmed the feasibility of laparoscopy in the treatment of intestinal malrotation.

Recently, in a retrospective case series of more than 40 children with an average age of 5.7 years, laparoscopy 
significantly reduced the time to full feeds and the hospital stay relative to open surgery, despite a high conversion rate (33\%) [6]. However, the data on the rates of success, conversion, and reoperation after laparoscopic management of malrotational abnormalities still are scarce, especially for neonates and younger children.

We report the clinical outcomes for laparoscopic correction of intestinal malrotation in a cohort of 37 patients treated at our institution.

\section{Methods}

\section{Patients}

Between February 1995 and September 2009, 45 patients underwent a laparoscopy for suspected intestinal malrotation. The indication for surgery was based on clinical signs and symptoms as well as ultrasound and an upper gastrointestinal contrast study.

\section{Surgery}

All surgeries were performed at the Wilhelmina Children's Hospital by an attending pediatric surgeon. The children all were hemodynamically stable. Surgery was performed as described previously [5] with the child in supine position, initially with the aid of three $5 \mathrm{~mm}$ trocars and later with two $3 \mathrm{~mm}$ trocars for instrumentation.

The vitality and rotational status of the intestines were assessed at laparoscopy. The intestines were rotated by gentle brushing, and Ladd's bands were divided where appropriate, widening the base of the mesentery as much as possible. Concurrent volvulus in 5 of 37 patients was managed laparoscopically in 4 cases. Appendectomy was performed in most cases. Feeding was resumed the day after surgery, and the child was discharged from the hospital after return to full feeding and full recovery.

\section{Statistics}

Results are presented as median or mean \pm standard error unless otherwise indicated.

\section{Results}

Patient characteristics

A total of 45 patients underwent laparoscopy for suspected intestinal malrotation. For eight of the patients, no malrotation was found, and their alternative diagnoses included gastrointestinal reflux and internal herniation. For the
Table 1 Patient characteristics

\begin{tabular}{ll}
\hline Average age: years (range) & $1.3 \pm 0.6(4$ days- \\
& 13 years $)$ \\
$<2$ months $(n)$ & 22 \\
$>2$ months $(n)$ & 15 \\
Male/female $(n)$ & $22 / 15$ \\
Average weight: kg (range) & $8.7 \pm 2.0(2.2-61)$ \\
Patients with concomitant congenital & 9 \\
disease $(n)$ & \\
\hline
\end{tabular}

remaining 37 patients, intestinal malrotation was confirmed at laparoscopy, and correction of the abnormalities was subsequently attempted. This group consisted of 22 boys and 15 girls with an average age of 1.3 years (range, 4 days to 13 years of age). Of these patients, 22 were 2 months old or younger. The average weight was $8.7 \mathrm{~kg}$ (range, 2.2$61 \mathrm{~kg}$ ). Nine patients had concomitant congenital or chromosomal abnormalities. The patient characteristics are summarized in Table 1.

\section{Surgery}

The average operating time was $115 \pm 7.8 \mathrm{~min}$ for all procedures. For eight patients (24\%), conversion to an open procedure was necessary, mainly due to problems with orientation and insufficient exposure for adequate broadening of the mesenteric pedicle. For two patients, conversion was necessitated by concomitant duodenal atresia, which was managed by duodenoduodenostomy. Interestingly, the rate of conversions did not differ significantly between patients younger than 2 months and older patients (23\% and $27 \%$, respectively).

\section{Postoperative outcome}

The median hospital stay was 11 days (range, 2-60 days). Postoperative clinical relapse due to recurrence of malrotation, volvulus, or both occurred for $19 \%$ of the laparoscopically treated patients $(n=7)$. These patients underwent laparoscopic $(n=1)$ or open $(n=6)$ redo surgery. For most of the patients, renewed derotation and additional division of Ladd's bands were necessary. The in-hospital and 30-day mortality rates were zero. One child with multiple congenital malformations died 1 year postoperatively due to a luxated percutaneous endoscopic gastrostomy catheter. Nine patients had postoperative complications other than recurrence of intestinal malrotation including fever necessitating administration of antibiotics, urinary tract infection, wound infection, and line sepsis.

The overall average hospital stay was $11 \pm 2.0$ days (range, 2-60 days). Several relatively long hospital stays 
Table 2 Summary of outcomes

\begin{tabular}{ll}
\hline Diagnostic laparoscopy $(n)$ & 45 \\
Malrotation $(n)$ & 37 \\
Average operating time $^{\mathrm{a}}$ (min) & $115 \pm 7.8$ \\
Conversion: $n(\%)$ & $9(25)$ \\
Due to concern for orientation $(n)$ & 5 \\
Due to concomitant duodenal atresia $(n)$ & 2 \\
Due to technical/other problems $(n)$ & 2 \\
Conversion in patient age $<2$ to $>2$ months $(\% / \%)$ & $23 / 27$ \\
Redo surgery: $n(\%)$ & $7(19)$ \\
Open procedure $(n)$ & 6 \\
Laparoscopic procedure ${ }^{\mathrm{b}}(n)$ & 1 \\
Hospital length of stay: days (range) & $11 \pm 2.0$ \\
& $(2-60)$
\end{tabular}

${ }^{a}$ Average operating time including conversions. Average time excluding conversions was $112 \pm 7.8 \mathrm{~min}$. For one child with concomitant hiatus hernia, a laparoscopic Thal procedure was performed in the one session with correction of malrotation (total operating time, $170 \min$ )

${ }^{\mathrm{b}}$ Redo laparoscopy performed for recurrent malrotation with derotation and additional division of Ladd's bands. Re-redo procedure (open) performed several days later for recurrent malrotation

were experienced by children with multiple congenital abnormalities requiring multidisciplinary care. The postoperative outcome data are summarized in Table 2.

\section{Discussion}

The rapid expansion of laparoscopic surgery in the pediatric population has led to decreased morbidity and a shorter hospital stay for a number of procedures [4]. With regard to the treatment of malrotation, however, there is a paucity of data on the laparoscopic approach.

Several questions need to be answered. First, is the laparoscopic technique feasible for diagnosis and correction of intestinal malrotation? This is especially relevant because in intestinal malrotation, a complete overview by "spreading out" the intestinal tract is mandated for the degree of nonrotation and the status of the mesentery to be assessed adequately. A number of case reports have detailed the technique required for adequate correction of rotational abnormalities in older children [7-10] and neonates [5], and also when volvulus is present [5, 11, 12].

Second, what are the results in terms of postoperative complications, redo surgery, and hospital stay when larger groups of patients are taken into account? Several retrospective case series have shown that laparoscopic treatment of intestinal malrotation is feasible in most cases, with good perioperative outcomes [6, 13-17]. These studies are summarized in Table 3.

Interestingly, two studies included only neonates or infants with volvulus, and both show that in well-selected patients, laparoscopy is feasible in such cases $[15,17]$. One larger series of 43 children (average age, 5.7 years) shows that laparoscopy is associated with a shortened time to full feeds and a shorter hospital stay but that a significant number of patients require conversion, reoperation, or both due to postoperative volvulus [6].

Our results show that laparoscopy is feasible even for correction of malrotation in both the neonatal and infant population (average age, 1.3 years). The rates of conversion are deemed acceptable and do not differ significantly by age group. As stated in previous studies [6, 15], we concur that outcome may depend largely on the ability to completely identify, assess, and correct the intestinal and mesenteric anatomy. In retrospect, given our relatively high rate of reoperations (19\%) and low rate of conversion, we suggest that conversion to an open procedure should be done with a low threshold when there is any doubt that an adequate result can be reached laparoscopically. Reoperations should not be performed laparoscopically.

Third, how do the results of laparoscopy compare with those of open correction in the longer term? Short-term results, including recurrence of intestinal malrotation and volvulus (usually within the first 6 months), have been described in most of the aforementioned studies. However, although the long-term complications of open correction (including adhesive bowel obstruction and chronic abdominal complaints) are well established [1, 18, 19], these remain to be determined for the laparoscopic procedure.

To answer these questions definitively, randomized and long-term research is warranted. In the meantime, we
Table 3 Review of case series (>3 patients included)

\begin{tabular}{lclcc}
\hline Study & $\begin{array}{l}\text { No. of patients } \\
\text { (no. with volvulus) }\end{array}$ & Average age & $\begin{array}{l}\text { Conversion } \\
(\%)\end{array}$ & $\begin{array}{l}\text { Reoperation } \\
(\%)\end{array}$ \\
\hline Fraser et al. [6] & 43 (unspecified) & 5.7 years & 33 & 2.4 \\
Palanivelu et al. [17] & $7(7)$ & $7-12$ years & 0 & 0 \\
Bass et al. [13] & $12(0)$ & 5 days-4 months & 0 & 0 \\
Mazziotti et al. [16] & $7(0)$ & 7 years & 0 & 0 \\
Draus et al. [14] & $8(0)$ & 10 weeks-25 years & 12 & 0 \\
Kalfa et al. [15] & $5(5)$ & 9 days & 20 & 20 \\
\hline
\end{tabular}


propose that laparoscopy is preferable when intestinal malrotation is suspected and appropriate for correction of malrotation provided a low threshold for converting to open surgery is maintained.

Disclosures Jeroen Hagendoorn, Daisy Vieira-Travassos, and David van der Zee have no conflicts of interest or financial ties to disclose.

Open Access This article is distributed under the terms of the Creative Commons Attribution Noncommercial License which permits any noncommercial use, distribution, and reproduction in any medium, provided the original author(s) and source are credited.

\section{References}

1. Aiken J, Oldham K (2005) Malrotation. In: Ashcraft K, Holcomb G, Murphy J (eds) Pediatric surgery. 4th ed. Elsevier Saunders, Philadelphia, pp. 435-447

2. Powell DM, Othersen HB, Smith CD (1989) Malrotation of the intestines in children: the effect of age on presentation and therapy. J Pediatr Surg 24:777-780

3. Prasil P, Flageole H, Shaw KS, Nguyen LT, Youssef S, Laberge JM (2000) Should malrotation in children be treated differently according to age? J Pediatr Surg 35:756-758

4. Ure BM, Bax NM, van der Zee DC (2000) Laparoscopy in infants and children: a prospective study on feasibility and the impact on routine surgery. J Pediatr Surg 35:1170-1173

5. van der Zee DC, Bax NM (1995) Laparoscopic repair of acute volvulus in a neonate with malrotation. Surg Endosc 9:11231124

6. Fraser JD, Aguayo P, Sharp SW, Ostlie DJ, St Peter SD (2009) The role of laparoscopy in the management of malrotation. J Surg Res 156:80-82

7. Frantzides CT, Cziperle DJ, Soergel K, Stewart E (1996) Laparoscopic Ladd procedure and cecopexy in the treatment of malrotation beyond the neonatal period. Surg Laparosc Endosc 6:73-75
8. Gross E, Chen MK, Lobe TE (1996) Laparoscopic evaluation and treatment of intestinal malrotation in infants. Surg Endosc 10:936-937

9. Lessin MS, Luks FI (1998) Laparoscopic appendectomy and duodenocolonic dissociation (LADD) procedure for malrotation. Pediatr Surg Int 13:184-185

10. Tsumura H, Ichikawa T, Kagawa T, Nishihara M (2003) Successful laparoscopic Ladd's procedure and appendectomy for intestinal malrotation with appendicitis. Surg Endosc 17:657-658

11. Brennan TV, Horn JK, Stollman NH (2002) Laparoscopic treatment of acute mesenteric torsion. Surg Endosc 16:1004

12. Yamashita $H$, Kato $H$, Uyama S, Kanata $T$, Nishizawa $F$, Kotegawa H, Watanabe T, Kuhara T (1999) Laparoscopic repair of intestinal malrotation complicated by midgut volvulus. Surg Endosc 13:1160-1162

13. Bass KD, Rothenberg SS, Chang JH (1998) Laparoscopic Ladd's procedure in infants with malrotation. J Pediatr Surg 33:279-281

14. Draus JM Jr, Foley DS, Bond SJ (2007) Laparoscopic Ladd procedure: a minimally invasive approach to malrotation without midgut volvulus. Am Surg 73:693-696

15. Kalfa N, Zamfir C, Lopez M, Forgues D, Raux O, Guibal MP, Galifer RB, Allal H (2004) Conditions required for laparoscopic repair of subacute volvulus of the midgut in neonates with intestinal malrotation: 5 cases. Surg Endosc 18:1815-1817

16. Mazziotti MV, Strasberg SM, Langer JC (1997) Intestinal rotation abnormalities without volvulus: the role of laparoscopy. J Am Coll Surg 185:172-176

17. Palanivelu C, Rangarajan M, Shetty AR, Jani K (2007) Intestinal malrotation with midgut volvulus presenting as acute abdomen in children: value of diagnostic and therapeutic laparoscopy. J Laparoendosc Adv Surg Tech A 17:490-492

18. Murphy FL, Sparnon AL (2006) Long-term complications following intestinal malrotation and the Ladd's procedure: a 15 year review. Pediatr Surg Int 22:326-329

19. Stauffer UG, Herrmann P (1980) Comparison of late results in patients with corrected intestinal malrotation with and without fixation of the mesentery. J Pediatr Surg 15:9-12 